\title{
High Density of Tumor-infiltrating B-Lymphocytes and Plasma Cells Signifies Prolonged Overall Survival in Adenocarcinoma of the Esophagogastric Junction
}

\author{
JULIANA KNIEF ${ }^{1 *}$, KATHARINA REDDEMANN $^{1 *}$, EKATERINA PETROVA $^{2}$, \\ TOBIAS HERHAHN ${ }^{1}$, ULRICH WELLNER ${ }^{2}$ and CHRISTOPH THORNS ${ }^{1}$ \\ ${ }^{1}$ Department of Pathology, Section of Hematopathology and Endocrine Pathology, \\ University Hospital of Schleswig-Holstein, Campus Luebeck, Luebeck, Germany; \\ ${ }^{2}$ Department of Surgery, University Hospital of Schleswig-Holstein, Campus Luebeck, Luebeck, Germany
}

\begin{abstract}
Background: Tumor-infiltrating lymphocytes (TILs) have been shown to be of prognostic significance in a variety of tumors. Not only T-cell, but also B-cell infiltration is commonly associated with improved survival. Materials and Methods: We assessed the density of tumor-infiltrating B-cells, as well as that of plasma cells, in 210 adenocarcinomas of the esophagogastric junction through immunohistochemical analysis using antibodies against CD20 and CD138. Results: No correlation between density of B-cells or plasma cells and various clinicopathologic features could be established. High density of tumor-infiltrating $B$-cells, as well as plasma cells, showed significantly better overall survival $(O S)$ compared to patients with no infiltrates ( $p=0.047$ and $p=0.022$, respectively). Cox proportional hazard analysis could verify B-cell infiltration as an independent prognostic factor (hazard ratio $(H R)=0.683 ; 95 \%$ confidence interval $(C I)=0.517-0.901 ; p=0.007)$. Conclusion: Plasma cell and B-cell infiltration correlates with prolonged OS and might identify a patient subset with favorable disease course.
\end{abstract}

In recent years, studies concerning the microenvironment of tumors, especially tumor-infiltrating lymphocytes (TILs), have been abundant. This microenvironment has been shown

This article is freely accessible online.

*These Authors contributed equally to this study.

Correspondence to: Juliana Knief, Department of Pathology, Section of Hematopathology and Endocrine Pathology, University Hospital of Schleswig-Holstein, Campus Luebeck, Luebeck, Germany. Tel: +49 4515003726, Fax: +49 4515003328, e-mail: Juliana.Knief@uksh.de

Key Words: Tumor infiltrating B-cells, tumor infiltrating plasma cells, tumor microenvironment, adenocarcinoma of the esophagogastric junction. to influence overall survival (OS), as well as relapse times, and probability of tumor recurrence $(1,2)$. However, most studies have focused on the relationship between T-cell infiltration and patients' outcome, while the role of tumor infiltrating B-lymphocytes (TIL-Bs), as well as plasma cells in this setting, is still poorly understood and less commonly investigated.

Not only the presence, but also the distribution pattern has been described as being crucial to prognosis: In carcinomas, immune cells are predominantly found in the stroma (3) and the formation of dense, follicle-like lymphocyte infiltrates (so-called tertiary lymphatic structures (TLSs), which arise in non-lymphoid tissues, often in the context of chronic inflammation) has been reported to have the strongest impact on prognosis and survival $(2,4,5)$.

T-lymphocytes (especially cytotoxic T-cells), as well as Blymphocytes, increase and establish the activation of antitumoral immunity (as an adaptive mechanism), leading to increased cell death in tumors and resulting in improved prognosis in patients with high levels of TILs $(2,6)$. Tumorassociated plasma cells have been described to have a significant impact on prognosis through modulation of the humoral immune response (7).

Up to date, most reports in the literature state a positive effect of TILs in respect to OS, relapse-free survival and association with favorable prognostic factors, as well as lower T-stage (8). High B-cell density is said to be associated with improved outcome in gastric, breast and colorectal cancer (9-11), as well as squamous cell carcinoma of the tongue (12), melanoma and hepatocellular carcinoma $(5,13)$. The same correlation has been shown for pancreatic adenocarcinomas, though here the impact was only measurable if cells were arranged in the pattern of TLSs (4, 14). High proportions of TILs have also been shown to be predictive of response to neoadjuvant therapy in breast cancer patients (15). 
However, there are also some studies showing that increased B-cell density is associated with higher recurrence frequencies in meningioma and prostate cancer, as well as with higher tumor grade and reduced OS in ovarian cancer or disease progression in breast cancer (16-19). Single studies state no prognostic effect of TIL-Bs (20).

Increased plasma cell density has been reported to be related to improved outcome in non-small cell lung cancer (NSCLC) and high-grade ovarian carcinoma $(7,21)$, while other studies showed an association with higher tumor grade and reduced OS in ovarian cancer (22).

The objective of this study was to analyze the potential prognostic value of tumor infiltrating immune cells in adenocarcinoma of the esophagogastric junction and their association with clinicopathological features.

\section{Materials and Methods}

Case selection. Two hundred and ten tumor samples (formalinfixed, paraffin-embedded tissue (FFPE) of adenocarcinomas of the esophagogastric junction with their epicentre within $2 \mathrm{~cm}$ on either side of the junction) were collected as part of standard clinical care at the University Hospital Schleswig-Holstein, Campus Luebeck, Germany, during 1992 and 2014. The study was approved by the local Ethics Committee of the University of Luebeck (reference 14242A).

Follow-up data was available for all patients with a mean followup period of 42.82 months (range $=0-227$ ).

Tissue microarray construction. Tissue microarrays (TMAs) were constructed using the manual QuickRay ${ }^{\circledR}$ kit (Unitma, Seoul, Korea) in accordance with the manufacturer's instructions. One representative core per tumor sample measuring $2 \mathrm{~mm}$ was dissected and mounted onto a tissue microarray. Appropriate positive and negative controls were included in each slide (kidney and tonsil tissue).

Immunohistochemistry. Immunohistochemical studies were performed on FFPE sections of the TMA according to a standard, three-step immunoperoxidase technique using the automated Menarini Bond Max System (Menarini Diagnostics, Berlin, Germany). The following antibodies were used: CD20 (clone L26, dilution 1:500; Cellmarque, Rocklin, CA, USA) and CD138 (clone B-A38, dilution 1:100; Biocare medical, Concord, CA, USA). All immunohistochemical stains were evaluated and a consensus was reached by two pathologists (JK, KR).

Scoring of cell density. Cell density was assessed semiquantitatively with the following scoring system: 0 (no detectable B- or plasma cells); $1+$ (scattered cells throughout the tumor); $2+$ (cells organized in follicles and/or dense sheets, forming TLSs) as previously described (14). Representative examples of scoring system are shown in Figure 1.

Statistical analysis. Statistical analysis was conducted using SPSS Statistics version 22 (IBM, Ehningen, Germany). Survival differences and outcome, as well as OS were analyzed with KaplanMeier estimates, including log-rank test, while correlation of CD20 and CD138 expression with different clinicopathologic features (univariate analysis) was determined with $\chi^{2}$ and Fisher's exact test, as well as Pearson's bivariate correlation. Cox regression analysis (proportional hazard ratio) was conducted to test for independence. Additionally, correlation between densities of cell infiltrates was evaluated by Spearman's Rho. A $p$-value $<0.05$ was considered statistically significant for all analyses.

\section{Results}

General aspects of the study group. The study population consisted of 210 individuals with 177 male (84.3\%) and 33 female patients $(15.7 \%)$. Ages ranged from 27 to 83 years with a mean age of 61.73 years (standard deviation \pm 10.663 ). Fifty-nine patients $(28.1 \%)$ received neoadjuvant therapy; for 67 patients $(31.90 \%)$, no data regarding possibly administered neoadjuvant therapy was available.

Density of B-cell and plasma cell infiltrates. Overall, 108 tumors $(51.4 \%)$ showed no plasma cell infiltrates, 60 cases $(28.6 \%)$ only scattered cells (score $1+$ ) and 36 tumors (17.1\%) had dense infiltrates (score 2+). Concerning Blymphocytes, 77 tumors $(36.7 \%)$ showed no infiltration, 84 cases $(40 \%)$ scattered (score $1+$ ) and 48 tumors $(22.9 \%)$ dense infiltrates (score $2+$ ). Six tumors $(2.9 \%)$ were not evaluable for plasma cell infiltration, 1 case $(0.5 \%)$ was not evaluable for B-lymphocytes.

Correlation of density of B-lymphocytes and plasma cells. Analysis of correlation between cell infiltrates applying Spearman's Rho revealed only a weak association with a correlation coefficient of 0.312 .

Correlation of $B$ - and plasma cell density with clinical and pathologic features. Univariate analysis of immune cell infiltrates and various features of the study group (i.e. gender, pT-stage, nodal stage, grading, lymphovascular invasion, perineural invasion, presence of distant metastases and histologic subtype according to WHO classification) revealed no significant correlation with any of the mentioned features. Appropriate data including $p$-values are summarized in Table I.

Plasma cell density in tumor microenvironment. Concerning CD138 expression/density of plasma cells in the tumor microenvironment, there was a significant difference in survival between scores $0,1+$ and $2+(p=0.045)$. Further analysis of patient groups with no plasma cell infiltration (score 0 ) against those with high density (score $2+$ ) showed that patients' OS was significantly better in cases with high plasma cell density ( $p=0.022)$, as shown in Figure 2 .

Survival times in scoring group 0 averaged 58.72 months $( \pm 8.308), 70.70$ months $( \pm 10.953)$ in scoring group $1+$ and 90.99 months $(+14.64)$ in group $2+$. 


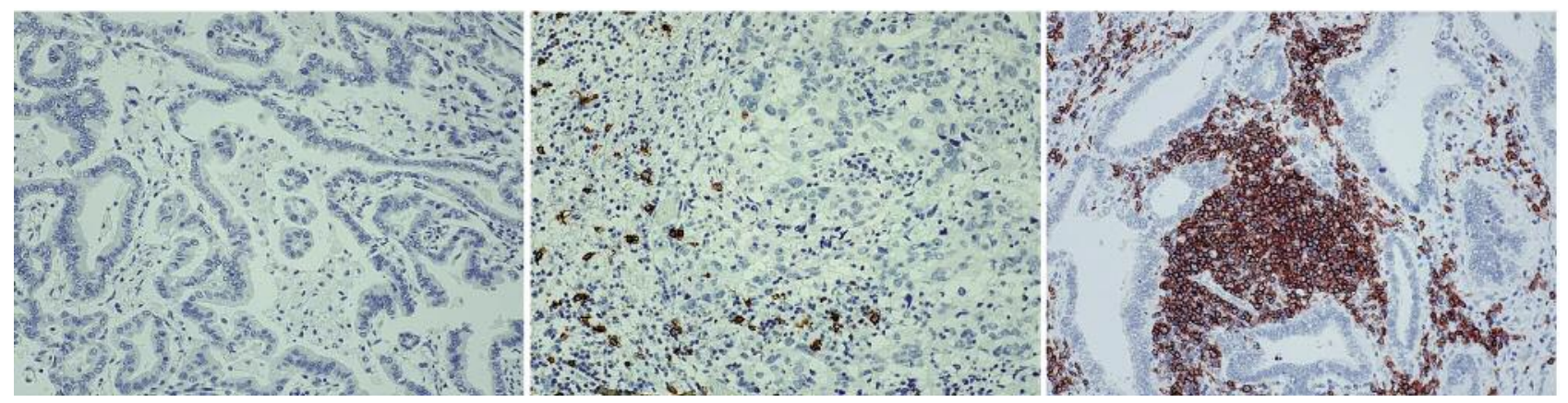

Figure 1. Assessment of cell density for B-lymphocytes and plasma cells. Left: Score 0 showing no discernible infiltrates. Middle: Score 1 showing scattered cells without dense infiltrates. Right: Score 2 showing dense infiltrates with formation of tertiary lymphatic structures (TLSs). CD20staining, magnification: $\times 200$.
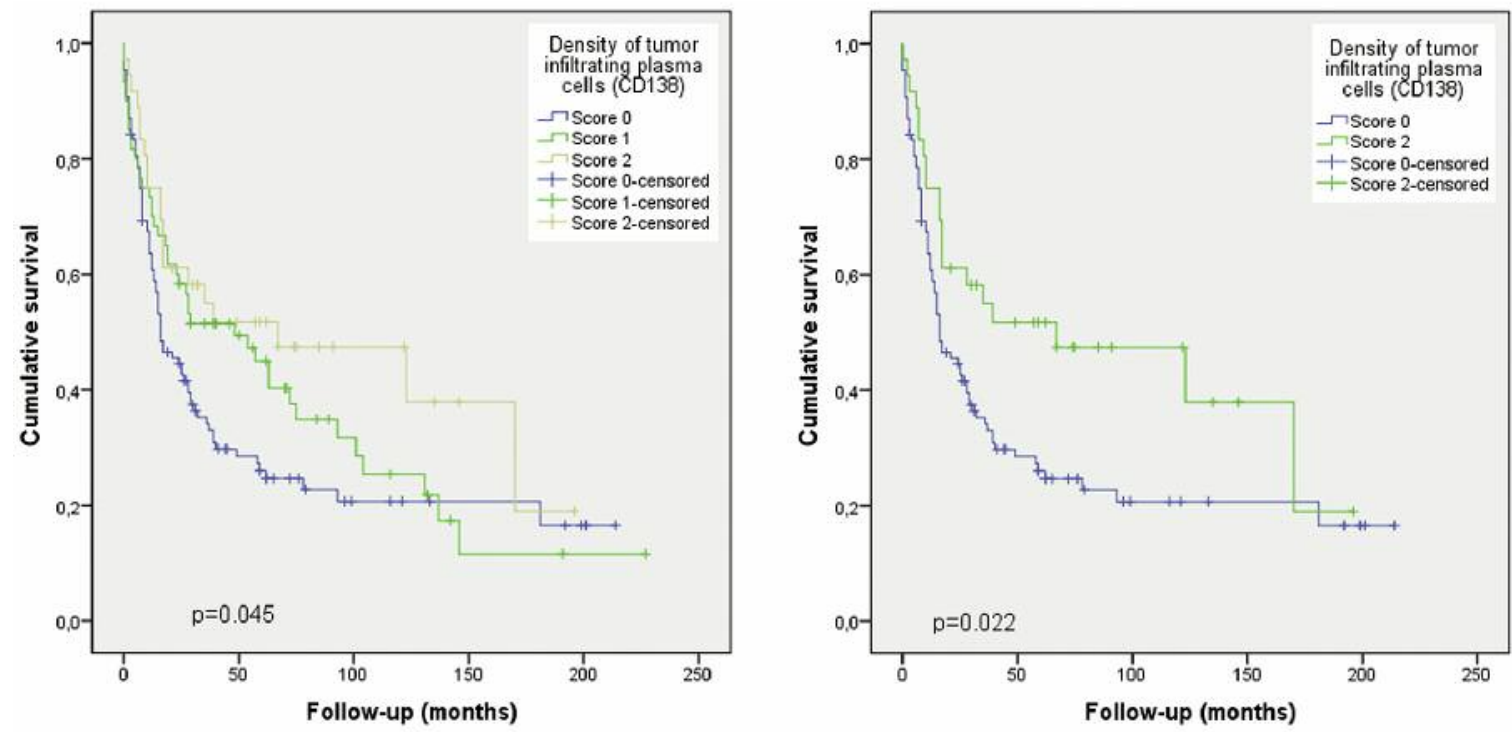

Figure 2. Kaplan-Meier curves showing survival differences in relation to density of tumor infiltrating plasma cells. Left: Density assessed by scores $0,1+$ and $2+$ with a p-value of 0.045. Right: Density assessed exclusively by scores 0 and $2+$ with a p-value of 0.022 .

B-cell density in tumor microenvironment. Concerning TILBs, results of analyses showed that there was no significant difference in patients' survival in score groups $0,1+$ and $2+$ $(p=0.132)$. However, analysis of patient groups 0 and $2+$ also revealed significantly better OS in patients with high B-cell density $(p=0.047)$, as shown in Figure 3.

Survival times in scoring group 0 averaged 67.69 months $( \pm 10.579), 63.1$ months $( \pm 8.505)$ in score group $1+$ and 83.41 months $( \pm 15.009)$ in group $2+$.

COX proportional hazard model, adjusted for age, gender and pT-stage revealed that plasma cell density was no independent prognostic factor but showed a trend towards improved survival (hazard ratio $(\mathrm{HR})=0.674 ; 95 \%$ confidence interval $(\mathrm{CI})=0.369-1.232 ; p=0.200)$. Interestingly though, for tumor infiltrating B-lymphocytes, independence could be demonstrated $(\mathrm{HR}=0.683 ; 95 \% \mathrm{CI}=0.517-0.901 ; p=0.007)$.

Impact of neoadjuvant therapy and high cell density on survival times. Patients with neoadjuvant therapy and high plasma cell density (score $2+, \mathrm{n}=10$ ) showed shorter (though not significantly reduced) OS (median survival time $=30.15 \pm 7.566$ months) than patients without neoadjuvant therapy $(n=12$; median survival $=88.13 \pm 23.980$ months) with a $p$-value of 0.512 . The results were also not significant when taking all three scoring groups into consideration $(p=0.715)$. 
Table I. Clinicopathologic characteristics of adenocarcinoma of the esophagogastric junction according to B-cell (CD20) and plasma cell (CD138) density. Comparison of tumors with no, scattered or dense infiltrates (score 0,1+and 2+) with various clinical and pathological features.

\begin{tabular}{|c|c|c|c|c|c|c|c|c|c|}
\hline \multirow[b]{2}{*}{ Characteristics } & & \multicolumn{3}{|c|}{ B-cell scores } & \multirow[b]{2}{*}{$p$-Value } & \multicolumn{3}{|c|}{ Plasma cell scores } & \multirow[b]{2}{*}{$p$-Value } \\
\hline & & 0 & $1+$ & $2+$ & & 0 & $1+$ & $2+$ & \\
\hline \multicolumn{10}{|l|}{ Gender } \\
\hline & Male & 67 & 70 & 39 & 0.664 & 91 & 49 & 31 & 0.835 \\
\hline & Female & 10 & 14 & 9 & & 17 & 11 & 5 & \\
\hline \multicolumn{10}{|l|}{$\begin{array}{l}\mathrm{pT} \\
\text { (low) }\end{array}$} \\
\hline & pT0 & 2 & 2 & 1 & 0.712 & 2 & 1 & 2 & 0.477 \\
\hline & pT1a & 3 & 3 & 1 & & 3 & 1 & 2 & \\
\hline & pT1b & 6 & 10 & 10 & & 11 & 9 & 7 & \\
\hline & pT2 & 12 & 17 & 9 & & 17 & 10 & 10 & \\
\hline \multirow[t]{3}{*}{ (high) } & pT3 & 47 & 44 & 20 & & 64 & 31 & 13 & \\
\hline & pT4a & 6 & 5 & 5 & & 8 & 6 & 2 & \\
\hline & pT4b & 1 & 3 & 2 & & 3 & 2 & 0 & \\
\hline \multicolumn{10}{|l|}{$\mathrm{pN}$} \\
\hline & $\mathrm{pNO}$ & 24 & 36 & 17 & 0.773 & 34 & 23 & 18 & 0.300 \\
\hline & $\mathrm{pN} 1$ & 14 & 13 & 6 & & 16 & 10 & 7 & \\
\hline & $\mathrm{pN} 2$ & 20 & 16 & 12 & & 31 & 12 & 4 & \\
\hline & $\mathrm{pN} 3$ & 19 & 19 & 12 & & 27 & 13 & 7 & \\
\hline \multicolumn{10}{|l|}{ LVSI } \\
\hline & Present & 50 & 41 & 26 & 0.091 & 66 & 28 & 19 & 0.160 \\
\hline & Absent & 26 & 43 & 22 & & 41 & 32 & 17 & \\
\hline \multicolumn{10}{|l|}{ Pn invasion } \\
\hline & Present & 22 & 21 & 8 & 0.299 & 30 & 14 & 6 & 0.377 \\
\hline & Absent & 54 & 63 & 40 & & 77 & 46 & 30 & \\
\hline \multicolumn{10}{|l|}{ Grade } \\
\hline & G1 & 1 & 1 & 0 & 0.326 & 2 & 0 & 0 & 0.465 \\
\hline & $\mathrm{G} 2$ & 23 & 13 & 12 & & 23 & 12 & 12 & \\
\hline & G3 & 33 & 45 & 21 & & 49 & 32 & 14 & \\
\hline \multicolumn{10}{|c|}{ Distant metastases } \\
\hline & Present & 14 & 19 & 13 & 0.397 & 26 & 15 & 4 & 0.558 \\
\hline & Absent & 36 & 32 & 18 & & 44 & 26 & 13 & \\
\hline \multicolumn{10}{|c|}{ WHO classification } \\
\hline & Tubular & 59 & 62 & 33 & 0.838 & 75 & 45 & 39 & 0.475 \\
\hline & Poorly cohesive & 9 & 11 & 6 & & 15 & 9 & 2 & \\
\hline & Other & 9 & 11 & 9 & & 18 & 6 & 5 & \\
\hline
\end{tabular}

LVSI, Lymphovascular space invasion; Pn, perineural.

In relation to density of B-lymphocytes, there was no detectable difference in OS for patients with neoadjuvant therapy and high B-cell density (score $2+, \mathrm{n}=15$ ) with a median survival of $73.70 \pm 12.718$ months, while patients without neoadjuvant therapy in scoring group $2(n=17)$ showed survival times of $76.84 \pm 19.507$ months $(p=0.411)$.

Correlation of cell density with most common histologic subtypes. Morphologically, 154 cases (73.3\%) were classified as tubular adenocarcinoma, $26(12.4 \%)$ as poorly cohesive carcinoma with signet ring cells and 30 cases $(14.3 \%)$ as other entities (i.e. undifferentiated, mucinous, papillary).
Survival times between tubular adenocarcinoma and poorly cohesive carcinoma did not differ significantly in regard to plasma cell infiltration (mean survival $=68.7 \mathrm{vs}$. 56.04 months; $p=0.111$ ) or B-cell density (mean survival=71.31 vs. 56.04 months; $p=0.2$ ).

There were no significant differences between histological subtypes concerning density of plasma cell $(p=0.349)$ or Bcell infiltration $(p=0.936)$.

Interestingly though, the subgroup of poorly cohesive adenocarcinoma showed significantly lower OS rates $(n=15$; mean survival $=16.07 \pm 6.452$ months) in comparison to tubular adenocarcinomas $(\mathrm{n}=75$; mean survival $=62.43 \pm 9.916$ months) when looking at cases where no plasma cell 

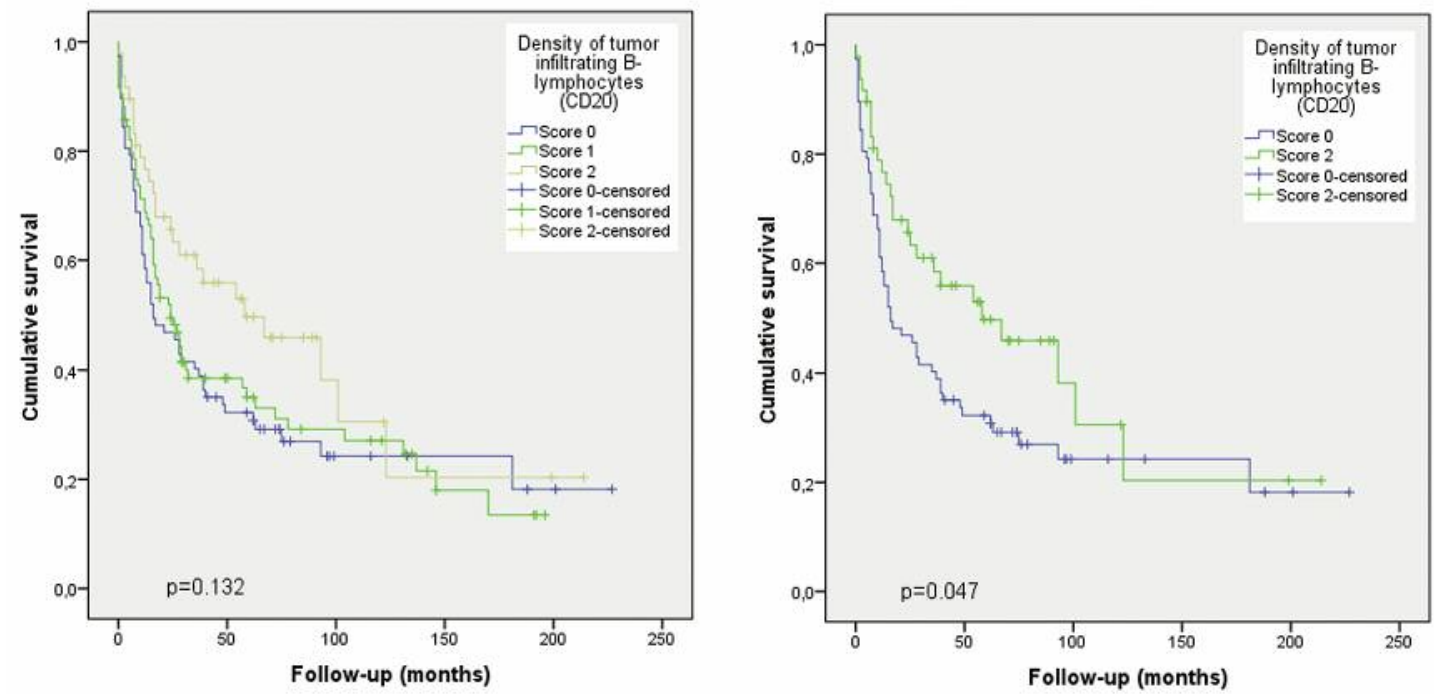

Figure 3. Kaplan-Meier curves showing survival differences in relation to density of tumor infiltrating B-lymphocytes. Left: Density assessed by scores $0,1+$ and $2+$ with a p-value of 0.132. Right: Density assessed exclusively by scores 0 and $2+$ with a p-value of 0.047 .
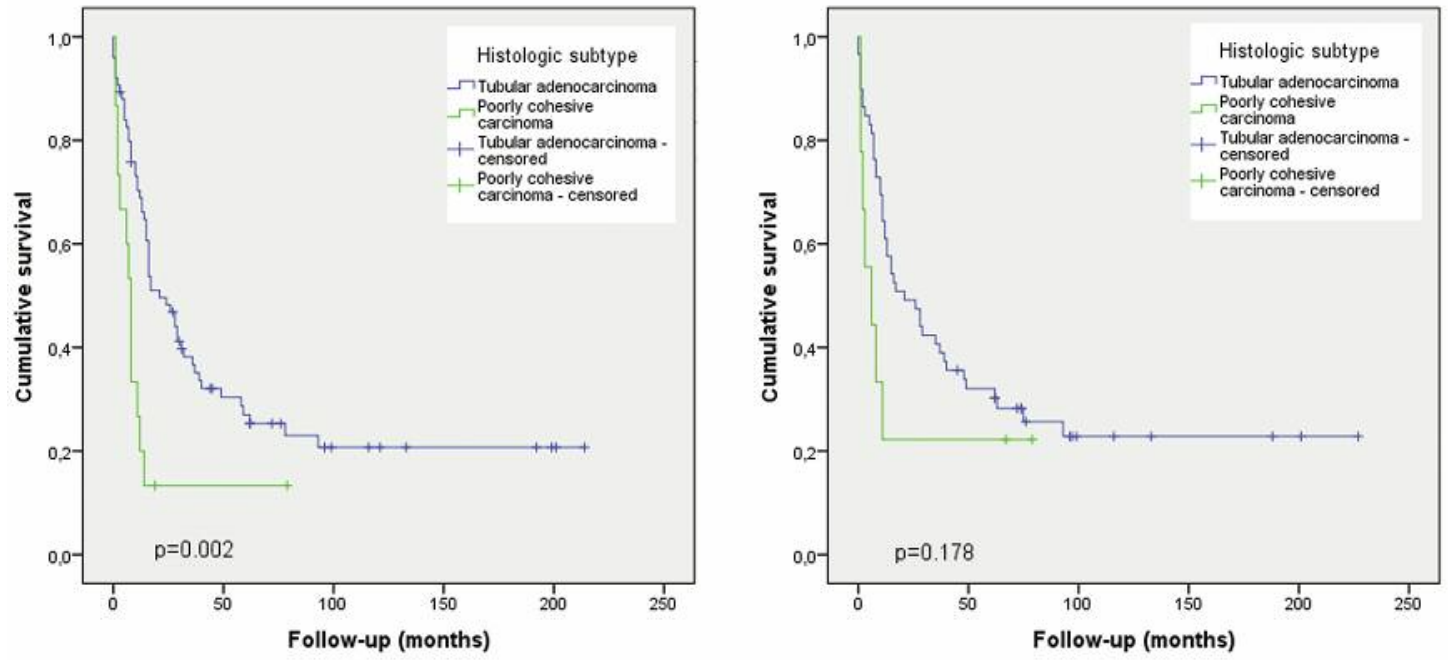

Figure 4. Kaplan-Meier curves showing survival differences in relation to histologic subtype. Left: Cases with no plasma cell infiltrates (score 0) show significantly better overall survival (OS) if tubular adenocarcinoma is present ( $p=0.002)$. Right: Cases without B-lymphocytes (score 0) show no disparity in OS between different histologic subtypes $(p=0.178)$.

infiltrates (score 0 ) could be detected $(p=0.002)$. No such correlation could be demonstrated for cases without tumor infiltrating B-cells $(p=0.178)$. Appropriate Kaplan-Meier curves are depicted in Figure 4.

\section{Discussion}

In our present study, the relation between density of B-cells and plasma cells in the tumor microenvironment and patients' outcome was investigated. The anti-tumorigenic properties of immune cells (T-, as well as B-lymphocytes) are well-established and high levels of TILs are commonly associated with improved survival in a variety of tumors, including gastric carcinomas $(2,23)$.

We demonstrated that, in adenocarcinoma of the esophagogastric junction, increased infiltration by B-cells and plasma cells in the stroma indicate prolonged survival, which has not been reported previously. For plasma cells, 
this held true for scattered, as well as dense, infiltrates ( $p=0.045$ and $p=0.022$, respectively), while, for B-cells, the effect was only discernible when so-called TLSs were present $(p=0.047)$. This is in concert with previous findings regarding pancreatic adenocarcinomas where only dense infiltrates and not scattered cells have significant impact on survival times (14), seemingly attributable to a more efficient and active anti-tumorigenic milieu (2). Not only cellular mechanisms mediated through B- and T-lymphocytes but also humoral activity -measured by plasma cell contentseem to have considerable influence on the hosts' inflammatory response to tumor cells. In fact, our results show plasma cells to be yet a stronger indicator of improved survival with even scattered infiltrates showing discernible differences in outcome compared to patients without detectable infiltrates (mean survival=70.70 vs. 58.72 months, respectively). However, this could not be confirmed by Cox regression where density of plasma cell infiltration did not constitute an independent prognostic factor (HR $=0.674 ; 95 \%$ $\mathrm{CI}=0.369-1.232 ; p=0.200)$. Nevertheless, independence could be demonstrated for B-cell infiltrates with a HR of 0.683 (95\% CI=0.517-0.901; $p=0.007$ ).

Interestingly, there was no correlation with any of the investigated clinical or pathological parameters on univariate analysis, especially no association with commonly prognosis-related features, such as lymphovascular invasion, lymph node involvement $(\mathrm{pN})$ and depth of invasion $(\mathrm{pT})$ or histologic type. This could partly be attributed to low number of cases in certain subgroups (i.e. pT0, pT1a or pT4b) and resulting limitations for statistical analysis. In other groups with higher case numbers, it might be proposed that the prognostic impact of tumor infiltrating lymphocytes is based on mechanisms in the tumor microenvironment that are fundamentally different (and independent) from those that cause survival differences through essentially tumorrelated mechanisms (as mentioned above).

There was no significant association between cell density and neoadjuvant therapy ( $p=0.715$ and $p=0.411$ ), although survival tended to be shorter in patients with neoadjuvant therapy and high cell densities (especially concerning plasma cells). Therapy itself might probably alter the microenvironment dramatically through increased tumor cell death and raised levels of host immune response. Further studies, preferably evaluating density of tumor-infiltrating cells pre- and post-therapy, could shed more light on this issue.

In conclusion, as high density of tumor-infiltrating plasma cells, as well as B-lymphocytes, correlate with prolonged OS, our results could provide further diagnostic utility in identifying patients with favorable disease course, as well as possible immunotherapeutic treatment strategies for a defined subset of patients. Additionally, investigations of larger cohorts might disclose further insight into the relationship between, e.g., histologic tumor type and density of plasma cells and B-lymphocytes or association with specific clinicopathologic features.

\section{Acknowledgements}

The Authors thank Annette Aufseß and Bettina Kummrow for their skilled and dedicated technical assistance.

\section{References}

1 Mohammed ZM, Going JJ, Edwards J, Elsberger B, Doughty JC and McMillan DC: The relationship between components of tumour inflammatory cell infiltrate and clinicopathological factors and survival in patients with primary operable invasive ductal breast cancer. Br J Cancer 107(5): 864-873, 2012.

2 Germain C, Gnjatic S and Dieu-Nosjean MC: Tertiary lymphoid structure-associated b cells are key players in anti-tumor immunity. Front Immunol 6: 67, 2015.

3 Harter PN, Bernatz S, Scholz A, Zeiner PS, Zinke J, Kiyose M, Blasel S, Beschorner R, Senft C, Bender B, Ronellenfitsch MW, Wikman H, Glatzel M, Meinhardt M, Juratli TA, Steinbach JP, Plate KH, Wischhusen J, Weide B and Mittelbronn M: Distribution and prognostic relevance of tumor-infiltrating lymphocytes (TILs) and PD-1/PD-L1 immune checkpoints in human brain metastases. Oncotarget 6(38): 40836-40849, 2015.

4 Hiraoka N, Ino Y, Yamazaki-Itoh R, Kanai Y, Kosuge T and Shimada K: Intratumoral tertiary lymphoid organ is a favourable prognosticator in patients with pancreatic cancer. Br J Cancer 112(11): 1782-1790, 2015.

5 Garg K, Maurer M, Griss J, Bruggen MC, Wolf IH, Wagner C, Willi N, Mertz KD and Wagner SN: Tumor associated b cells in cutaneous primary melanoma and improved clinical outcome. Hum Pathol, 2016.

6 Suemori T, Susumu N, Iwata T, Banno K, Yamagami W, Hirasawa A, Sugano K, Matsumoto E and Aoki D: Intratumoral CD8+ lymphocyte infiltration as a prognostic factor and its relationship with cyclooxygenase 2 expression and microsatellite instability in endometrial cancer. Int J Gynecol Cancer 25(7): 1165-1172, 2015.

7 Lohr M, Edlund K, Botling J, Hammad S, Hellwig B, Othman A, Berglund A, Lambe M, Holmberg L, Ekman S, Bergqvist M, Ponten F, Cadenas C, Marchan R, Hengstler JG, Rahnenfuhrer $\mathrm{J}$ and Micke P: The prognostic relevance of tumour-infiltrating plasma cells and immunoglobulin kappa $\mathrm{c}$ indicates an important role of the humoral immune response in non-small cell lung cancer. Cancer Lett 333(2): 222-228, 2013.

8 Silina K, Rulle U, Kalnina Z and Line A: Manipulation of tumour-infiltrating b cells and tertiary lymphoid structures: A novel anti-cancer treatment avenue? Cancer Immunol Immunother 63(7): 643-662, 2014.

9 Hennequin A, Derangere V, Boidot R, Apetoh L, Vincent J, Orry D, Fraisse J, Causeret S, Martin F, Arnould L, Beltjens F, Ghiringhelli $\mathrm{F}$ and Ladoire S: Tumor infiltration by TBET+ effector t cells and DD20+ B cells is associated with survival in gastric cancer patients. Oncoimmunology 5(2): e1054598, 2016.

10 Nelson BH: $\mathrm{Cd} 20+$ b cells: The other tumor-infiltrating lymphocytes. J Immunol 185(9): 4977-4982, 2010. 
11 Berntsson J, Nodin B, Eberhard J, Micke P and Jirstrom K: Prognostic impact of tumour-infiltrating b cells and plasma cells in colorectal cancer. Int J Cancer, 2016.

12 Lao XM, Liang YJ, Su YX, Zhang SE, Zhou XI and Liao GQ: Distribution and significance of interstitial fibrosis and stromainfiltrating B cells in tongue squamous cell carcinoma. Oncol Lett 11(3): 2027-2034, 2016.

13 Garnelo M, Tan A, Her Z, Yeong J, Lim CJ, Chen J, Lim KH, Weber A, Chow P, Chung A, Ooi LL, Toh HC, Heikenwalder M, $\mathrm{Ng}$ IO, Nardin A, Chen Q, Abastado JP and Chew V: Interaction between tumour-infiltrating $\mathrm{B}$ cells and $\mathrm{T}$ cells controls the progression of hepatocellular carcinoma. Gut, 2015.

14 Castino GF, Cortese N, Capretti G, Serio S, Di Caro G, Mineri R, Magrini E, Grizzi F, Cappello P, Novelli F, Spaggiari P, Roncalli M, Ridolfi C, Gavazzi F, Zerbi A, Allavena P and Marchesi F: Spatial distribution of b cells predicts prognosis in human pancreatic adenocarcinoma. Oncoimmunol 5(4): e1085147, 2016.

15 Issa-Nummer Y, Loibl S, von Minckwitz G and Denkert C: Tumor-infiltrating lymphocytes in breast cancer: A new predictor for responses to therapy. Oncoimmunology 3: e27926, 2014.

16 Romaniuk A and Lsmall u CiUM: Immune microenvironment as a factor of breast cancer progression. Diagn Pathol 10: 79, 2015.

17 Ding Y, Qiu L, Xu Q, Song L, Yang S and Yang T: Relationships between tumor microenvironment and clinicopathological parameters in meningioma. Int J Clin Exp Pathol 7(10): 69736979,2014

18 Woo JR, Liss MA, Muldong MT, Palazzi K, Strasner A, Ammirante M, Varki N, Shabaik A, Howell S, Kane CJ, Karin $\mathrm{M}$ and Jamieson CA: Tumor infiltrating B-cells are increased in prostate cancer tissue. J Transl Med 12: 30, 2014.
19 Yang C, Lee H, Jove V, Deng J, Zhang W, Liu X, Forman S, Dellinger TH, Wakabayashi M, Yu H and Pal S: Prognostic significance of B-cells and PSTAT3 in patients with ovarian cancer. PLoS One 8(1): e54029, 2013.

20 Flammiger A, Bayer F, Cirugeda-Kuhnert A, Huland $\mathrm{H}$, Tennstedt P, Simon R, Minner S, Bokemeyer C, Sauter G, Schlomm $\mathrm{T}$ and Trepel M: Intratumoral $\mathrm{T}$ but not B lymphocytes are related to clinical outcome in prostate cancer. APMIS 120(11): 901-908, 2012.

21 Kroeger DR, Milne K and Nelson BH: Tumor-infiltrating plasma cells are associated with tertiary lymphoid structures, cytolytic $\mathrm{t}$-cell responses, and superior prognosis in ovarian cancer. Clin Cancer Res, 2016.

22 Lundgren S, Berntsson J, Nodin B, Micke P and Jirstrom K: Prognostic impact of tumour-associated b cells and plasma cells in epithelial ovarian cancer. J Ovarian Res 9: 21, 2016.

23 Kang BW, Seo AN, Yoon S, Bae HI, Jeon SW, Kwon OK, Chung HY, Yu W, Kang H and Kim JG: Prognostic value of tumor-infiltrating lymphocytes in Epstein-Barr virus-associated gastric cancer. Ann Oncol 27(3): 494-501, 2016.
Received August 9, 2016

Revised August 22, 2016

Accepted August 23, 2016 